\title{
Uma proposta de baixo custo para experimentos com raios catódicos ${ }^{+*}$
}

\author{
Defferson Rodrigues Martins das Neves \\ Bianca Alves Pereira ${ }^{1}$ \\ Sabrina Alves Pereira \\ Mestrandos em Ensino de Ciências e Matemática \\ Thaís Cyrino de Mello Forato ${ }^{1}$ \\ André Amaral Gonçalves Bianco ${ }^{1}$ \\ Universidade Federal de São Paulo \\ Diadema - SP
}

\section{Resumo}

Este trabalho apresenta uma proposta de adaptação de um dos experimentos sobre a natureza dos raios catódicos realizado ao final do século XIX, especificamente, aquele apresentado em livros didáticos e de divulgação científica como "o experimento de Thomson" para o cálculo da relação carga/massa do elétron. Nossa proposta utiliza materiais com custos inferiores aos de kits de experimentos disponíveis no mercado internacional e apresenta uma descrição pormenorizada da sua construção e operação, concorrendo, em vários aspectos, como solução para alguns dos motivos relacionados à pouca utilização dos experimentos nas aulas de ciências: o custo elevado dos materiais e dos equipamentos, a falta de laboratórios e a falta de habilidade dos professores. A elaboração do aparato experimental é ainda acompanhada do desenvolvimento matemático necessário à sua utilização e da indicação dos vários fenômenos físicos que podem ser tratados paralelamente à sua implementação. Com a adaptação experimental, fomos capazes de medir e calcular o campo magnético a que os elétrons são submetidos no interior de um tubo de raios catódicos, a diferença de potencial entre catodo e anodo no tubo (tensão de aceleração dos elétrons), a deflexão magnética

\footnotetext{
${ }^{+}$A proposal with low cost for cathode ray experiments

* Recebido: maio de 2018.

Aceito: março de 2019.

1 E-mails: deffersonr@yahoo.com.br; alves-pereirabs@hotmail.com; thaiscmf@gmail.com; andrequim@yahoo.com.br
} 
que os elétrons sofrem, e, com uma boa aproximação, a velocidade de translação dos elétrons e a relação carga/massa dessas partículas.

Palavras-chave: Relação Carga/Massa do Elétron; Raios Catódicos; J. J. Thomson e a Estrutura da Matéria.

\begin{abstract}
This paper presents a proposal for the adaptation of one of the experiments on the nature of the cathod rays performed at the end of the 19th century, specifically the one presented in textbooks and scientific dissemination as "the Thomson experiment" for the calculation of charge Imass ratio of the electron. Our proposal uses materials at a lower cost than experiment kits available on the market and presents a detailed description of its construction and operation, and contributes in several respects as a solution to some of the reasons related to the low utilization of experiments in science classes: the high cost materials and equipment, the lack of laboratories and the lack of ability of teachers. The elaboration of the experimental apparatus is also accompanied by the mathematical development necessary for its use and the indication of the various physical phenomena that can be treated in parallel with its implementation. With the experimental adaptation, we were able to measure and calculate the magnetic field to which the electrons are subjected inside a cathode ray tube, the potential difference between cathode and anode in the tube (electron acceleration voltage), the magnetic deflection that the electrons undergo, and to a good approximation the speed of translation of the electrons and the chargel mass ratio of these particles.
\end{abstract}

Keywords: Charge/Mass Ratio of the Electron; Cathode Rays; J. J. Thomson and the Structure of Matter.

\title{
I. Introdução
}

A partir de assuntos abordados na disciplina de Estrutura da Matéria de um Curso de Licenciatura em Física, realizamos uma adaptação experimental para o cálculo da relação carga/massa (e/m) das partículas constituintes dos raios catódicos: o BDS e/m apparatus ${ }^{2}$.

\footnotetext{
${ }^{2}$ Aparelhagem batizada com as iniciais dos autores idealizadores da adaptação do experimento da relação carga massa do elétron.
} 
No lugar de "reproduzir" os experimentos na forma como foram idealizados, ao final do século XIX, por Johann Emil Wiechert (1861-1928), Walter Kaufmann (1871-1947) e Joseph John Thomson (1856-1940), entre outros, ou suscitarmos a compra dos caros kits $\mathrm{e} / \mathrm{m}$ apparatus disponíveis no mercado internacional, propomos a realização de um experimento com redução de custos e que permite a manipulação por parte dos estudantes. Esse experimento possibilita a observação de fenômenos identificados à época, calcular variáveis físicas e obter o valor da relação carga/massa do elétron com boa aproximação do valor de referência.

O experimento possibilita ainda uma abordagem histórica do período e do ambiente no qual foi desenvolvido. Discutindo aspectos tais como as inúmeras contribuições de diferentes pesquisadores, as influências das sociedades científicas locais e as limitações impostas pelo aparato experimental. Contribuindo assim, para uma visão mais adequada da História das Ciências e da produção do conhecimento científico.

As partes e o funcionamento de um televisor com tubo de raios catódicos proveem tanto o material utilizado na montagem quanto o auxílio na explicação dos fenômenos observados no experimento. Somando-se aos componentes que devem ser adquiridos a parte, o custo total dos materiais (valores apurados no segundo semestre de 2018 no Brasil) equivale a aproximadamente três por cento do valor comercial dos kits adquiridos por universidades e escolas de educação básica.

\section{Quadro teórico}

O objetivo do ensino e da aprendizagem das Ciências está diretamente relacionado ao seu papel na vida dos alunos, seja na dimensão individual ou social (DELIZOICOV; ANGOTTI, 2000): facilitando a compreensão da tecnologia atual; promovendo o entendimento das Ciências como uma produção social; e fornecendo ferramentas para que possam refletir e tomar decisões sobre o uso do conhecimento científico, entre outros.

Contudo, Moreira (2014) elenca uma série de problemas relacionados ao ensino de ciências na atualidade: o desestímulo a uma aprendizagem significativa crítica; a centralização no docente; o modelo de narrativa; o treinamento em resolução de exercícios previsíveis; e a falta de reflexão sobre as concepções prévias dos discentes. Para o caso específico do Ensino da Física, esse autor cita ainda a formação precária dos professores, a desatualização dos conteúdos trabalhados e das tecnologias apresentadas e a interpretação equivocada sobre a natureza das ciências.

Ainda sobre o assunto, dentre uma série de outros fatores, Carvalho e Gil-Pérez (2011) também apontam a deficiência na formação de professores como um dos problemas do ensino de ciências atual e Gaspar (2014) especifica, dentre essas deficiências, a falta de habilidade para elaborar e realizar experimentos. Marcondes (2007) expõe a opinião de professores sobre o tema esclarecendo que 
ao mesmo tempo em que defendem a relevância das atividades experimentais, os professores argumentam sobre as dificuldades para sua execução. O número reduzido de aulas [...], a falta de material para a orientação, a inexistência de laboratório, a falta de formação docente, a escassez de bibliografia específica e atualizada, a falta de tempo para o preparo das atividades (p. 27).

Pesquisadores (CARVALHO; GIL-PÉREZ, 2011; CARVALHO, 2004; POZO; CRESPO, 2009; DELIZOICOV; ANGOTTI; PERNANBUCO, 2011) indicam muitas possibilidades para se lidar com esses e outros problemas no Ensino de Ciências. Neste artigo, vamos recorrer às particularidades de experimentos aplicados ao Ensino de Ciências.

\section{II.1 Atividades experimentais no Ensino de Ciências}

Muitos pesquisadores concordam que o ensino das ciências experimentais, seja na educação básica, seja no ensino superior, não pode prescindir da prática da experimentação (ARAÚJO; ABIB, 2003; CARVALHO, 2010; GASPAR, 2014; MARCONDES, 2007; DELIZOICOV; ANGOTTI; PERNANBUCO, 2011; TRIVELATO; SILVA, 2011). Esses mesmos autores destacam algumas das finalidades da prática experimental no Ensino de Ciências: motivar os alunos, capacitá-los na resolução de problemas e nas técnicas e metodologias da pesquisa científica, facilitar a compreensão de conceitos, desenvolver habilidades manipulativas, trabalhar coletiva e cooperativamente, estabelecer conflitos cognitivos entre a observação e as concepções prévias dos alunos, compreender o desenvolvimento da ciência, inclusive entendendo o papel do erro e da não linearidade em sua construção, compreender a limitação e o caráter não definitivo do conhecimento científico, estabelecer os limites da aplicação e da validade de uma teoria, incorporar conceitos da matemática, compreender a tecnologia atual atribuindo significado à fórmulas, conceitos e leis, entre outros. No entanto, a prática experimental não pode ser vazia de significado e sua aplicação deve sempre estar fundamentada em um ou mais dos seguintes aspectos: (i) oferecer fundamentos para que estudantes compreendam que a experimentação não é neutra e sim baseada em princípios (teorias e hipóteses) anteriores à constatação dos fenômenos (GIL-PÉREZ et al., 2001); (ii) os experimentos devem proporcionar diferentes graus de liberdade aos alunos, em negação à experimentação realizada com um roteiro tipo "receita de bolo" (CARVALHO, 2010), ou então, conforme Heering (2014) aponta, os experimentos "não serão usados para produzir novo conhecimento, mas servirão apenas para demonstrar o conhecimento já estabelecido" (p. 144, tradução nossa); (iii) saber transitar da mesa de experiência para o conceitual a fim de extrair o abstrato do concreto (BACHELARD, [1938] 1996); e, (iv) compreender que um experimento não se presta apenas a comprovação de uma teoria, mas também pode apresentar uma aplicação desta (KUHN, 2013). 
Importa também, considerar que durante uma experimentação nem tudo ocorre da forma esperada, imprevistos acontecem, e os docentes devem estar preparados para desfazerem a imagem de que o fracasso na realização material do experimento represente um fracasso intelectual daqueles que se propuseram a realizá-lo (HEERING, 2014; BACHELARD, [1938] 1996), já que a sensação de que algo saiu errado pode ter sido apenas o prelúdio de uma nova perspectiva ou possibilidade de explicação para o fenômeno (KUHN, 2013).

Aliar a reprodução de experimentos com o estudo adequado de alguns episódios históricos permite ainda, compreender as inter-relações entre ciência, tecnologia e sociedade, mostrando que a ciência faz parte de um desenvolvimento histórico, de uma cultura, de um mundo humano, sofrendo influências e influenciando, por sua vez, muitos aspectos da sociedade (MARTINS, 2006). Ainda que fortemente baseada em observação e experimentação, as Ciências são construídas por seres humanos com seus valores e crenças acerca do mundo. A abordagem histórica permite compreender tanto a fundamentação de teorias científicas, como o lado humano da atividade científica.

Os conceitos, modelos e teorias das ciências resultam em muitos debates e controvérsias, inúmeras hipóteses e refutações, além de trabalhos que envolvem vários pesquisadores, muitos deles anônimos e desconhecidos. Essas características da natureza das Ciências são muito diferentes da imagem propagada que envolve o mito das descobertas súbitas ou ocasionais, ou por meio de insight atribuídos a homens geniais. Como exemplo, Thomson (1903), Whittaker (1910) e Townsend (1915) relatam uma longa história sobre a investigação da natureza da descarga elétrica no interior de tubos com gases rarefeitos, com muitas teorias e hipóteses que tentavam explicar e entender aquele espetacular fenômeno, e vários cientistas envolvidos, caracterizando um episódio da história das Ciências que pode ilustrar muito bem o seu caráter coletivo e não linear. Partindo dessas ideias, essa proposta buscou caminhos para o desenvolvimento do experimento para determinar a relação carga/massa do elétron, de modo a atender algumas dessas recomendações.

\section{Metodologias envolvidas na pesquisa}

O caminho investigativo que orientou essa proposta partiu de um estudo empírico para o desenvolvimento da proposta experimental, envolvendo os experimentos sobre as partículas constituintes dos raios catódicos realizados no final do século XIX, inspirada pelo conteúdo da disciplina Estrutura da Matéria de um curso de formação de professores de Física.

Vislumbrou-se a possibilidade inovadora de se adaptar um dos experimentos realizados por Thomson, fazendo uso de material com custo inferior ao dos tradicionais kits internacionais, como um televisor com tubo de raios catódicos e componentes eletrônicos comuns. Isso se deu pelo fato de o televisor possuir todos os itens (em uma versão moderna) presentes nos aparatos utilizados pelos pesquisadores que estudavam a natureza dos raios catódicos no final do século XIX: tubo de raios catódicos, bobinas de deflexão magnética, placas de deflexão elétrica (em algumas versões) e fonte de tensão aceleradora de elétrons. 
Essa montagem experimental alternativa ofereceu novos modos de se mensurar variáveis, requerendo uma diferente proposição no desenvolvimento matemático para se obter a relação carga/massa do elétron.

\section{III.1 Metodologia para o desenvolvimento do experimento}

O desenvolvimento do aparato experimental foi precedido por um aprofundamento sobre o equipamento histórico, as técnicas utilizadas, os fenômenos e os conceitos físicos abordados no experimento que se desejava adaptar. Esta pesquisa inicial foi baseada em fontes primárias (THOMSON, [1897] 1958; THOMSON, [1903] 2012) e em literatura especializada de referência sobre a conceituação atual (TIPLER; MOSCA, 2009; SERWAY; JEWETT, 2004).

Houve ainda a necessidade de se conhecer como os experimentos para determinação da relação carga/massa do elétron são realizados na atualidade, compreender o funcionamento dos kits, os equipamentos que o compõem, quais as grandezas físicas observadas e analisadas e os valores de mercado dos mesmos (CARLIN et al., 2009; KRAFTMAKHER, 2015; SILVA; SANTOS; DIAS, 2011).

O detalhamento sobre o funcionamento dos televisores que utilizam tubos de raios catódicos, especialmente sobre a etapa geradora da imagem (ZANETIC; MENEZES; HOSOUME, 2000; THOMSON; CALLICK, 1959), permitiu realizar comparações entre estes, as partes que compunham os aparatos científicos de 1897 e os kits comerciais, e, pela analogia, inferir a possibilidade da adaptação.

A seguir, delimitou-se o método para a realização das medições das tensões, campo magnético e distância de deslocamento do feixe de elétrons, e ainda, a substituição de instrumentos de medida (gaussímetro e ponta de prova de alta tensão) e da bobina de deflexão, todos com custo relativamente elevado, por opções com valores acessíveis.

Como será detalhado na seção seguinte, nossa proposta se enquadra numa posição intermediária entre a reprodução de experimentos históricos e aquela em que se atem essencialmente aos fenômenos estudados (como exemplo, os atuais kits comerciais e/m apparatus), o que suscitou a necessidade de uma matematização diferente daquelas empregadas nas duas modalidades citadas. Nesse sentido, o desenvolvimento das equações foi apoiado em Tipler e Mosca (2009); Weinberg (2003) e em Wher e Richard-Jr (1965).

A realização de uma série de testes e medições para o cálculo da relação carga/massa do elétron finalizou a etapa de desenvolvimento do experimento. 


\section{Resultados: proposta para o experimento e dados experimentais}

Nesta seção, apresentamos as três abordagens para o experimento com raios catódicos, a versão apresentada em livros didáticos, os kits comerciais e/m apparatus, e o resultado desta pesquisa, o BDS e/m apparatus.

\section{IV.1 O experimento histórico sobre raios catódicos}

Muitos livros didáticos, materiais de divulgação científica e textos acadêmicos, ao se referirem aos experimentos de Thomson sobre a composição dos raios catódicos, mostram a imagem do assim chamado, "clássico experimento" do tubo de descargas elétricas, no qual um feixe de raios catódicos é deflexionado magneticamente por um arranjo de bobinas e eletricamente por um conjunto de placas paralelas (Fig. 1). Nesse aparato, o feixe de raios catódicos é produzido por partículas que são atraídas por um campo elétrico formado por uma diferença de potencial entre catodo e anodo. Essas partículas atravessam as fendas do anodo e vão chocar-se contra a outra extremidade do tubo.

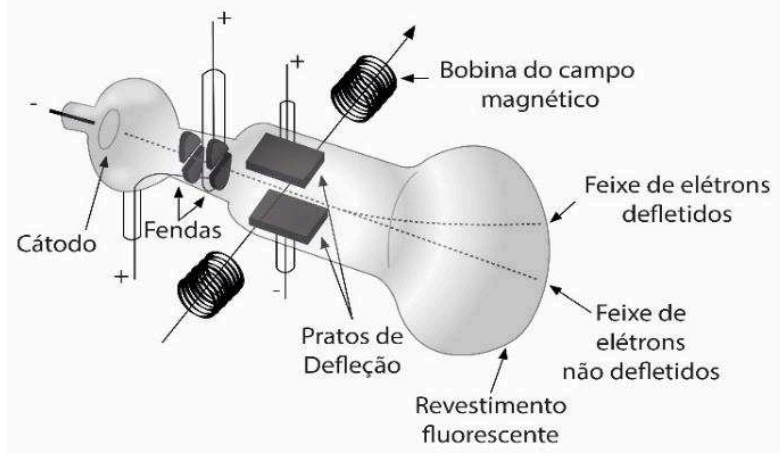

Fig. 1 - Imagem representativa do aparato utilizado por Thomson. Fonte: autores.

Essa é uma descrição excessivamente simplista, que acaba por fomentar uma imagem distorcida do empreendimento científico, como se, com um único experimento, o cientista fosse capaz de obter todas as características dos raios catódicos (GIL-PÉREZ, 2001; MARTINS, 2006).

Diferente do que é comumente divulgado, Thomson não realizou apenas um, mas uma série de experimentos para que pudesse avaliar a relação da carga/massa das partículas constituintes dos raios catódicos. Em cada um desses experimentos Thomson verificou ou comparou uma determinada característica desses raios, tais como: caráter negativo, velocidade, influência de campos elétrico e magnético na deflexão, a relação entre a tensão de aceleração (diferença de potencial entre o catodo e o anodo) e a deflexão do feixe. 
O mais conhecido dos aparatos de Thomson (Fig. 1) foi utilizado primeiramente para repetir os experimentos realizados por Heinrich Rudolf Hertz (1857-1894) na investigação da deflexão dos raios catódicos resultante de uma força elétrica (THOMSON, [1903] 2012). Depois, acrescido de um par de bobinas dispostos externamente ao tubo e em uma posição perpendicular à das placas de deflexão, o mesmo aparato foi utilizado para inferir a velocidade e a relação carga/massa das partículas constituintes dos raios.

A solução matemática apresentada por Thomson ([1897] 1958) para o cálculo da relação carga/massa $(e / m)$ e da velocidade das partículas $(v)$ em Cathode Rays não é adequada para o plano desse artigo, assim, preferimos demonstrar como chegar aos mesmos resultados por meio de uma aproximação, apoiados nas propostas de Tipler e Mosca (2009), Weinberg (2003) e Wher e Richard-Jr (1965).

A demonstração matemática apresentada a seguir adota algumas aproximações, com a finalidade de garantir que alunos do ensino médio compreendam o que está sendo exposto, no entanto, não há um comprometimento conceitual sobre o conteúdo científico/físico. $\mathrm{Na}$ seção IV.3, apresentaremos um complemento da demonstração matemática, em função da nossa adaptação experimental.

\section{IV.2 A deflexão magnética e elétrica de partículas carregadas em movimento no interior dos tubos de raios catódicos}

Nos livros textos do ensino superior (TIPLER; MOSCA, 2009; WHER; RICHARDJR, 1965), o cálculo da deflexão magnética de uma partícula em movimento no interior de um tubo de raios catódicos, considerando perpendicular as direções da trajetória das partículas e o campo magnético, é dado pela equação:

$$
d_{m a g}=\frac{1}{2}\left(\frac{q B l l}{m v}\right)+\left(\frac{q B l L}{m v}\right)
$$

Onde, $d_{m a g}$ é a deflexão magnética sofrida pelo feixe de elétrons, $q$ é a carga elétrica da partícula, $B$ é o campo magnético que age sobre o feixe de partículas, $l$ é o comprimento da região na qual o feixe de partículas está sob influência do campo magnético (região de deflexão, ou o região delimitada pelo diâmetro da bobina), $m$ é a massa da partícula, $v$ é a velocidade de translação da partícula e $L$ é o comprimento da região de arrasto (espaço compreendido entre o limite da bobina e a tela do tubo de raios catódicos). A demonstração da obtenção dessa equação pode ser consultada em Tipler et al. (2009, p. 199) ou em Wher et al. (1965, p. 34). No entanto, o escopo deste artigo se refere ao ensino médio, para o qual julgamos mais adequada a demonstração a seguir. 
As próximas explicações tomarão como base o tubo de raios catódicos da Fig. 1. De acordo com Weinberg (2003), considerando o pequeno espaço que uma partícula viajará, desde sua origem (catodo) até a tela do tubo de raios catódicos (aproximadamente $200 \mathrm{~mm}$ no tubo utilizado em nosso experimento), e as intensidades das forças elétricas e magnéticas a que esta partícula é submetida no interior do tubo, podemos desconsiderar, ainda que exista, a força da gravidade agindo sobre uma partícula com massa da ordem de grandeza de um elétron. Efetivamente, a força da gravidade da Terra interfere no resultado das medições, mas de forma pouco significativa para as nossas intenções.

Partindo da segunda lei de Newton, e supondo que uma força $F$ (a força magnética exercida pelo campo magnético gerado pelas bobinas) é exercida sobre as partículas dos raios catódicos em uma direção perpendicular ao movimento desses, temos que essas partículas sofrem uma aceleração na direção de $F$ com módulo $a=F / m$, onde $m$ é a massa da partícula, e $a$, a aceleração; então, se estes raios forem expostos a essa força, por um tempo $t$, eles irão adquirir uma componente de velocidade perpendicular a seu movimento original, com magnitude

$$
v_{\text {perpendicular }}=t \cdot a=\frac{t F}{m}
$$

Supondo que as partículas tenham uma componente de velocidade $v$ na direção original dos raios, e atravessem com essa velocidade a "região de deflexão" de comprimento $l$ (Consulte a Fig. 3 para uma melhor compreensão sobre a região de deflexão), onde são expostos a uma força $F$. Sabendo que velocidade é distância pelo tempo, $v=l / t$, então, o tempo de duração no qual a partícula é acelerada é

$$
t=\frac{l}{v}
$$

Substituindo a equação (3) na equação (2), temos

$$
v_{\text {perpendicular }}=\frac{F l}{m v}
$$

Após deixar a região de deflexão, os raios viajam através de uma "região de arrasto" de comprimento $L$, em uma direção muito próxima a direção original dos raios ${ }^{3}$, e com uma componente de velocidade na sua direção original ainda igual a $v$. Pela mesma razão que levou à equação (3), o tempo gasto na região de arrasto é

$$
T=\frac{L}{v}
$$

\footnotetext{
${ }^{3}$ Aqui, lançamos mão de mais uma aproximação. Como a região ocupada pelo campo magnético (diâmetro da bobina de deflexão) é pequena considerando a velocidade das partículas que a atravessam, o tempo passado por essas partículas no interior desse campo será pequeno e, portanto, o desvio da trajetória original também será. Essa deflexão inicial é desconsiderada em nossos cálculos. No entanto, a demonstração completa considerando ambos os desvios, pode ser consultada em Tipler e Mosca (2009, p. 199-200) e em Wher e Richard, Jr (1965, p. 34-39).
} 
Durante este tempo, as partículas são também movimentadas em uma direção perpendicular à sua direção original com uma velocidade $v_{\text {perpendicular }}$; então, o deslocamento $d$ do caminho original dos raios quando eles alcançam o fim da região de arrasto é

$$
d=T v_{\text {perpendicular }}
$$

Substituindo as equações (4) e (5) na equação (6) temos

$$
d=\left(\frac{L}{v}\right)\left(\frac{F l}{m v}\right) \text { ou } d=\frac{F l L}{m v^{2}}
$$

Agora, vamos avaliar a distância de deflexão considerando a ação de uma força elétrica ou de uma força magnética.

Supondo que os raios catódicos sejam partículas carregadas com uma carga elétrica $e$, então a força elétrica exercida sobre esta carga $e$, por um campo elétrico $E$, é obtida por

$$
F_{\text {elétrica }}=e E
$$

E, de acordo com a equação (7), esta força produzirá uma deflexão nos raios na extremidade do tubo igual a

$$
d_{\text {elétrica }}=\frac{e E l L}{m v^{2}}
$$

A força magnética exercida pelo campo magnético $B$ sobre uma partícula de carga $e$ e velocidade $v$ é $\boldsymbol{F}=q \boldsymbol{v} \times \boldsymbol{B}$ (considerando-se o caráter vetorial das grandezas envolvidas). Contudo, no experimento, o vetor velocidade das partículas está em uma direção perpendicular ao vetor campo magnético (a força age essencialmente em um ângulo reto à direção original dos raios), dessa forma, podemos calcular a força magnética pelo produto de $e, v$ e $B$,

$$
F_{\text {magnética }}=e v B
$$

De acordo com a equação (7), essa força produz um deslocamento no fim do tubo igual à

$$
d_{\text {magnética }}=\frac{e B l L}{m v}
$$

Perceba que uma das potências de $v$ do denominador da equação (7) foi cancelada com a potência de $v$ da equação (10).

Relacionando as equações (9) e (11) dessa forma,

$$
\frac{d_{\text {magnética }}}{d_{\text {elétrica }}}=\frac{\frac{e B l L}{m v}}{\frac{e E l L}{m v^{2}}}=\frac{B v}{E} \text { ou } v=\left(\frac{E}{B}\right)\left(\frac{d_{\text {magnética }}}{d_{\text {elétrica }}}\right)
$$

Para calcular a velocidade das partículas, em um primeiro momento, ajustam-se os campos elétricos e magnéticos de forma que as deflexões causadas por ambos sejam iguais (ou seja, os raios deveriam viajar em linha reta), dessa forma a equação (12) se tornaria $v=(E / B)$, e pode-se inferir a velocidade dos raios catódicos a partir dos valores de $E$ e $B^{4}$.

\footnotetext{
${ }^{4}$ Ao final do século XIX, os cientistas já podiam calcular o campo magnético gerado por bobinas paralelas bem como o campo elétrico formado por placas metálicas paralelas, eles precisavam conhecer as características cons-
} 
Substituindo a equação (12) na equação (11) temos

$$
d_{\text {magnética }}=\frac{e B l L}{\frac{m E d_{\text {magnética }}}{B d_{\text {elétrica }}}}=\frac{e B^{2} l L d_{\text {elétrica }}}{m E d_{\text {magnética }}}
$$

Escrevendo a equação (13) para que $e / m$ fique em evidência, temos

$$
\frac{e}{m}=\frac{E\left(d_{\text {magnética }}\right)^{2}}{B^{2} l L\left(d_{\text {elétrica }}\right)}
$$

Essa é a fórmula utilizada para calcular a relação $e / m$ a partir das deflexões elétrica e magnética, uma das técnicas utilizadas por cientistas ao final do século XIX.

Na próxima seção, após uma sucinta explanação a respeito das pesquisas sobre reconstruções de experimentos históricos, apresentamos uma breve explicação sobre a utilização dos kits comerciais e/m apparatus e uma matematização alternativa para a proposta experimental de custo reduzido, que semelhantemente aos kits comerciais, tem o feixe de partículas deflexionado apenas pelo campo magnético.

\section{IV.3 Os kits comerciais e o BDS e/m apparatus}

Segundo Medeiros e Monteiro Jr (2011), existem ao menos duas correntes direcionadas às reconstruções experimentais históricas: a do grupo de Oldenburg, com a tentativa de reproduzir fielmente os detalhes dos aparelhos envolvidos nos experimentos, assim como a de produzir textos que contemplem ao máximo a atmosfera cultural da época; e a do grupo de Minnesota, buscando preservar a essência dos fenômenos estudados sem deter-se em dificuldades tidas como de segunda ordem.

Contudo, conforme Heering (1999), apud Medeiros e Monteiro Jr (2011), do ponto de vista educacional, a proposta de Oldenburg é de execução extremamente complexa, pois a tentativa de reprodução fiel dos aparelhos utilizados e de reprodução do contexto teórico e cultural de disputas que deem conta de toda aquela complexidade contida nos instrumentais utilizados esbarra, por vezes, em enormes dificuldades a serem contornadas.

Uma terceira corrente é a proposta por Medeiros e Monteiro Jr (2011) ampliando as ideias do grupo de Minnesota. Com base nela, decidimos fazer algumas modificações no conhecido experimento de Thomson sobre a relação carga/massa das partículas constituintes dos raios catódicos. Preservando a essência do seu funcionamento, introduzindo consideráveis elementos de simplificação construtiva, de modo que possa ser executado em sala de aula, além de ensejarem importantes comparações históricas, devido às modificações propiciarem situações interpretativas que variam conforme o contexto, que também podem ser discutidas com os alunos.

trutivas de bobinas e placas e a corrente elétrica e diferença de potencial relacionadas respectivamente às bobinas e às placas. 
Atualmente, para a realização do experimento de Thomson, algumas empresas comercializam os chamados e/m apparatus, kits especificamente desenvolvidos para esse fim. A um custo médio de 2,5 mil dólares, os kits devem ser importados e são frequentemente compostos por tubo de raios catódicos, bobinas de Helmholtz, fonte de alta tensão, fonte de baixa tensão e, algumas vezes, por um multímetro.

Nesses kits, não existem as placas para deflexão dos raios catódicos por meio da força elétrica, sendo então necessária uma matematização diferente para que a relação carga/massa do elétron possa ser calculada apenas utilizando-se a deflexão causada pela força do campo magnético. Esse desenvolvimento matemático está presente nos manuais que acompanham os kits e no trabalho de Kraftmakher (2015), e tem estreita relação com os aspectos construtivos do tubo de raios catódicos utilizado. Veja a Fig. 2 para uma avaliação de um desses kits.

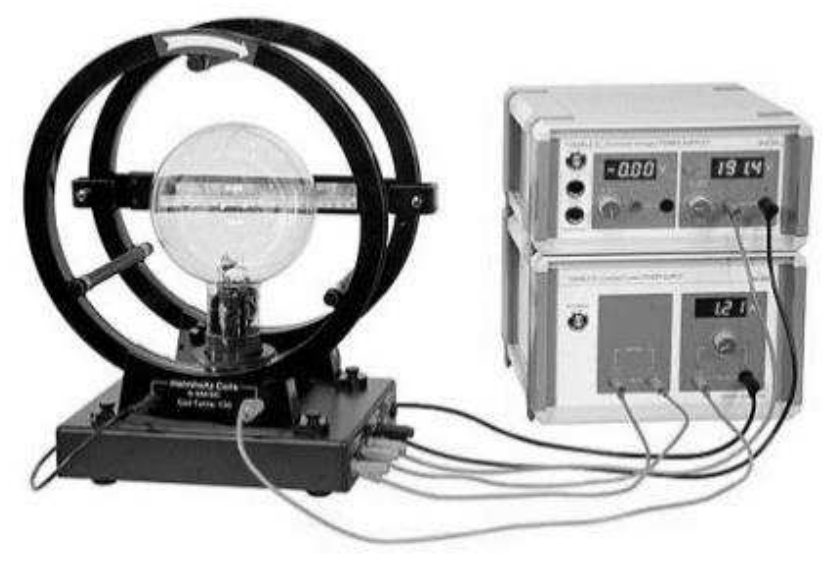

Fig. 2 - Exemplo de kit comercial e/m apparatus. Fonte:

<https://www.pasco.com/prodComparelelectron-charge-to-mass-ratio-system/index.cfm>.

A forma do tubo de raios catódicos utilizado em nossa adaptação se aproxima mais à daqueles utilizados por cientistas da última década do século XIX, no entanto, assim como os e/m apparatus atuais, não estão presentes as placas de deflexão elétrica, sendo, portanto, necessária uma matematização que difere, tanto daquela utilizada nos experimentos do final do século XIX, quanto da utilizada como os kits comerciais.

A Fig. 3 facilitará a identificação e compreensão das variáveis presentes na demonstração. 


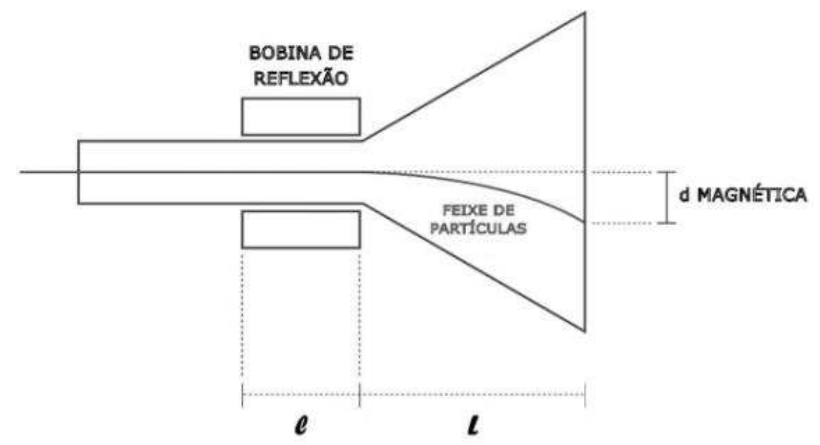

Fig. 3 - Identificação de algumas das variáveis utilizadas no desenvolvimento da fórmula para o cálculo de elm. Fonte: autores.

Partindo-se, então, da equação (11) $d_{\text {magnética }}=\frac{e B l L}{m v}$ temos que,

$$
\frac{e}{m}=\frac{d_{\text {magnética }} v}{B l L}
$$

Sabendo que $e V=1 / 2 m v^{2}$, sendo $V$ a tensão de aceleração das partículas, ou, a diferença de potencial entre catodo e anodo ${ }^{5}$. Resolvemos para $e / m$, resultando em

$$
\frac{e}{m}=\frac{v^{2}}{2 V}
$$

Substituindo a equação (16) na equação (11), obtemos

$$
d_{\text {magnética }}=\frac{v B l L}{2 V}
$$

Escrevendo a equação (17) para que $v$ fique em evidência, resulta em

$$
v=\frac{d_{\text {magnética }} 2 V}{B l L}
$$

Temos agora uma nova incógnita, $V$, a tensão de aceleração dos elétrons, que pode ser medida com um multímetro e uma ponta de prova de alta tensão (por se tratar de uma tensão da ordem de quilovolts). Então, por meio da equação (18), agora podemos calcular a velocidade das partículas e então voltar à equação $(15)$ e calcular a relação $e / m$. Outra opção seria substituir a equação (18) diretamente na equação (15) obtendo

$$
\frac{e}{m}=\frac{d_{\text {magnética }}^{2} 2 V}{(B l L)^{2}}
$$

a equação utilizada com o BDS $e / m$ apparatus de custo reduzido proposto nesta pesquisa. No Quadro 1, relacionamos todas as variáveis dessa equação, suas descrições e como podem ser medidas ou calculadas.

\footnotetext{
5 Este foi o método utilizado por Kaufmann e Wiechert para o cálculo da relação carga/massa das partículas constituintes dos raios catódicos.
} 
Quadro 1 - Descrição das variáveis.

\begin{tabular}{|c|c|c|}
\hline $\begin{array}{l}\text { Variá- } \\
\text { veis }\end{array}$ & Descrição & Como pode ser medido/calculado? \\
\hline$d_{m a g}$ & $\begin{array}{l}\text { Deflexão magnética sofrida pelos raios } \\
\text { catódicos. Em metros. }\end{array}$ & $\begin{array}{l}\text { Com uma régua diretamente na tela do tubo de raios } \\
\text { catódicos (em nossa proposta, é a tela do televisor). }\end{array}$ \\
\hline$V$ & $\begin{array}{l}\text { Tensão de aceleração das partículas. } \\
\text { Em volts. }\end{array}$ & $\begin{array}{l}\text { Com uma ponta de prova de alta tensão e um multí- } \\
\text { metro. }\end{array}$ \\
\hline$B$ & $\begin{array}{l}\text { Intensidade do campo magnético for- } \\
\text { necido pelas bobinas de deflexão mag- } \\
\text { nética. Em tesla. }\end{array}$ & $\begin{array}{l}\text { Com um Gaussímetro (em nossa proposta o campo } \\
\text { magnético será medido com um Gaussímetro de } \\
\text { baixo custo construído a partir de um sensor de efeito } \\
\text { hall). }\end{array}$ \\
\hline$l$ & $\begin{array}{l}\text { Comprimento da região na qual o feixe } \\
\text { de partículas está sob influência do } \\
\text { campo magnético (comprimento da } \\
\text { região de deflexão, ou o diâmetro da } \\
\text { bobina). Em metros. }\end{array}$ & Com uma régua. \\
\hline$L$ & $\begin{array}{l}\text { Comprimento da região de arrasto } \\
\text { (espaço compreendido entre o limite } \\
\text { da bobina e a tela do tubo de raios } \\
\text { catódicos). Em metros. }\end{array}$ & $\begin{array}{l}\text { Com uma régua. } \\
\text { Atenção: na região de exibição das imagens (tela), o } \\
\text { vidro que compõe o tubo de raios catódicos possui } \\
\text { uma espessura aproximada de } 3 \mathrm{~mm} \text {. Ao realizar a } \\
\text { medição da área de arrasto considerar que o elétron } \\
\text { se choca com a superfície interior da tela, que dista } 3 \\
\text { mm da superfície exterior. }\end{array}$ \\
\hline$v$ & $\begin{array}{l}\text { Velocidade das partículas. Em metros } \\
\text { por segundo. }\end{array}$ & Pode ser calculada através da equação (18). \\
\hline
\end{tabular}

\section{IV.4 A construção e utilização do BDS e/m apparatus de custo reduzido}

Em uma linha que mais se aproxima das ideias sugeridas por Medeiros e Monteiro Jr (2011), nossa proposta para a adaptação do experimento de Thomson parte da utilização de um modelo antigo de televisor, que utiliza um tubo de raios catódicos para exibir imagens. $\mathrm{O}$ modelo utilizado possui uma tela de 5 polegadas em preto e branco (Fig. 4), pode ser encontrado com alguma dificuldade em lojas de departamentos, porém com maior facilidade em brechós e lojas de utensílios usados.

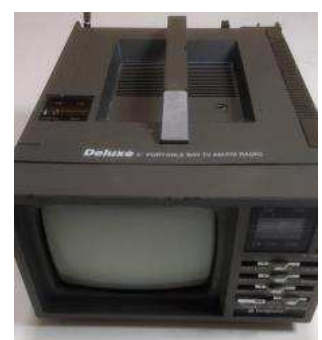

Fig. 4 - Modelo de TV utilizado no experimento. Fonte: acervo dos autores.

$\mathrm{Na}$ verdade, qualquer televisor preto e branco que utilize tubo de raios catódicos é útil para a adaptação. No entanto, a escolha por esse modelo se justifica pelas baixas tensões encontradas em grande parte de seus circuitos (da ordem de $20 \mathrm{~V}$ ), o que favorece a segurança do experimento. 
Para a realização do nosso experimento são necessários (com valores médios na grande São Paulo, em dezembro de 2018): 1 televisor preto e branco usado de 5 polegadas ( $\mathrm{R} \$ 20,00), 1$ multímetro digital ( $\mathrm{R} \$ 40,00), 1$ fonte de tensão variável de $6 \mathrm{~V}$ ou mais e 1,5 A $(\mathrm{R} \$ 160,00)^{6}, 1$ fonte de $5 \mathrm{~V}$ (por exemplo, as utilizadas como carregador de celulares) (R\$ 10,00), 1 circuito integrado sensor de efeito hall (A1308, SS49E) ou equivalente (R\$10,00), 13 resistores de valores variados de 2 ou 3 watts ( $\mathrm{R} \$ 0,50$ cada) (os resistores são utilizados na construção da ponta de prova de alta tensão, os valores de resistência necessários serão esclarecidos durante o texto), 3 garras jacaré vermelhas e 3 pretas ( $\mathrm{R} \$ 1,00$ cada), 3 plugs banana macho ( $\mathrm{R}$ \$ 1,00 cada), material para a construção da ponta de prova de alta tensão ( $\mathrm{R}$ \$ 25,00), algumas ferramentas manuais tais como alicate, chave de fenda, ferro de solda, fios para as ligações e fita isolante. Tais materiais formam o kit que intitulamos como BDS e/m apparatus (total $=\mathrm{R} \$ 236,50$ ou $\mathrm{R} \$ 176,50$ caso se opte pela construção da fonte variável).

Simplificadamente, um televisor funciona recebendo sinais (ondas eletromagnéticas) provenientes das antenas das emissoras de TV, processando, amplificando e exibindo esses sinais na forma de imagens em sua tela (parte frontal do tubo de raios catódicos) e na forma de sons, em seus alto-falantes. Dentre as diversas etapas que constituem um equipamento de $\mathrm{TV}$, a que nos interessa conhecer com um pouco mais de detalhamento é a geração da imagem no tubo de raios catódicos, ou tubo de imagem.

As Fig. 5 e 6 nos auxiliarão na explicação, utilize-as como referências para identificar as partes citadas e sua aparência.

Na etapa geradora da imagem, três são os componentes que nos interessam, o tubo de raios catódicos, as bobinas de deflexão e o flyback.

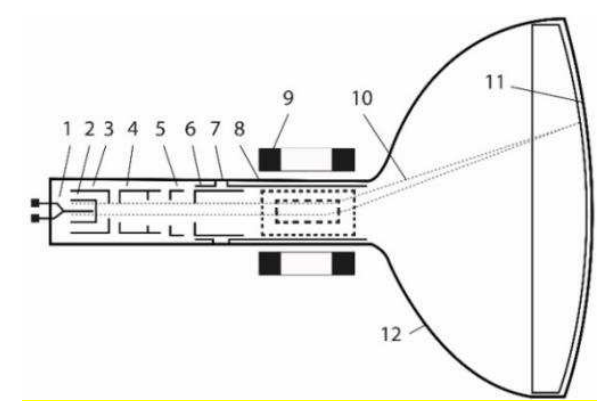

Fig. 5 - A geração da imagem no tubo de raios catódicos. Esquema de um cinescópio para uma televisão em preto e branco. (1) Filamento aquecedor do catodo, (2) catodo, (3) eletrodo de controle, (4) eletrodo acelerador, (5) primeiro anodo, (6) segundo anodo, (7) revestimento condutor (Aquadag), (8) bobinas de deflexão vertical do feixe, (9) bobinas de deflexão horizontal do feixe, (10) feixe de elétrons, (11) tela, (12) terminal do segundo anodo. Fonte: autores.

\footnotetext{
6 A fonte variável pode também ser construída pelos alunos ou pelo professor, a um custo aproximado de $\mathrm{R} \$ 100,00$. Alguns exemplos podem ser obtidos em Braga (2005).
} 


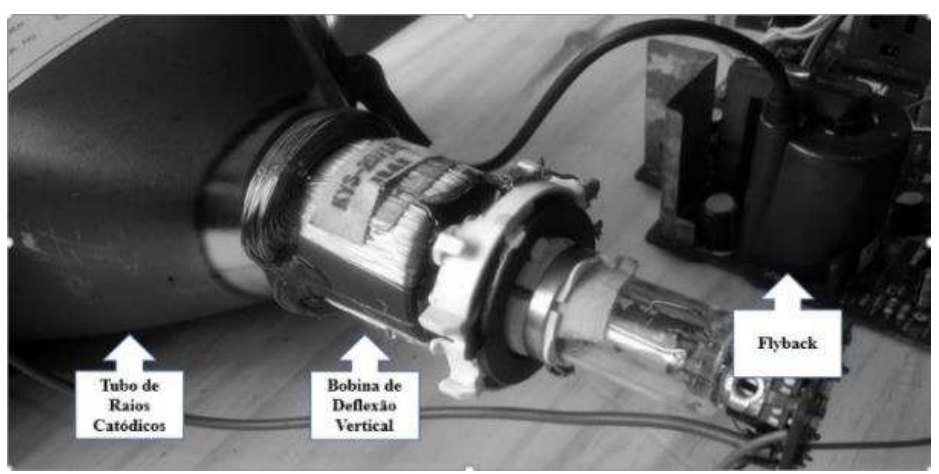

Fig. 6 - Tubo de raios catódicos, bobina de deflexão vertical e flyback. Fonte: acervo dos autores.

Zanetic, Menezes e Hosuome (2000) e Thomson e Callick (1959), descrevem o tubo de raios catódicos como um componente que tem por função transformar uma corrente elétrica variável em imagem na tela da TV. No "pescoço" ou colo do tubo está o canhão eletrônico ou emissor de raios catódicos, composto por filamento de aquecimento, catodo e anodo acelerador (entre outros que não são relevantes para nosso projeto).

O catodo é composto por um material com baixa função de extração, que quando aquecido pelo filamento de tungstênio é capaz de emitir uma grande quantidade de elétrons por efeito termiônico ${ }^{7}$.

Estes elétrons são então acelerados em direção à outra extremidade do tubo (tela), pela ação do campo elétrico formado entre o catodo (conectado a um potencial negativo da TV) e o anodo (conectado a uma alta tensão positiva). Nota-se que os tubos de descarga utilizados pelos cientistas do final do século XIX (Fig. 1) é que deram origem aos "atuais" tubos de raios catódicos das TVs (SMITH, 2001).

A alta tensão positiva a que nos referimos é obtida por meio do flyback (um transformador especializado que pode trabalhar com tensões da ordem de dezenas de $\mathrm{kV}$ e com frequências da ordem de dezenas de quilohertz) e retificada por um diodo de alta tensão.

Como no interior do tubo de imagens quase não existe matéria para desviar os elétrons ejetados do anodo o feixe tende a mover-se em linha reta e sempre chocar-se com o centro da tela ${ }^{8}$. A tela, por sua vez, é revestida internamente por um material que emite luz ao receber o impacto dos elétrons (efeito da fotoluminescência), gerando assim as imagens em uma televisão preto e branco. A quantidade de luz emitida (ou os tons de cinza) dependerá da velocidade de incidência dos elétrons e da sua quantidade.

\footnotetext{
7 As fontes bibliográficas consultadas adotam a concepção de que os elétrons que partem do catodo possuem uma velocidade inicial igual a zero e não discutem, por exemplo, a ideia de que partículas ejetadas por efeito termiônico devem adquirir alguma velocidade em uma direção desconhecida. Desse modo, a fim de facilitar a compreensão do fenômeno, esses aspectos também não serão considerados pela nossa proposta.

8 De fato, ainda que a distância entre a fonte de elétrons (catodo) e seu destino (a tela) seja muito pequena, a ação do campo magnético da terra pode influenciar a trajetória do feixe. Isso pode ser perfeitamente percebido durante o experimento, variando-se a posição o tubo de raios catódicos de forma que o feixe de elétrons esteja,
} 
Porém, um único ponto no centro da tela não atende aos propósitos da geração de imagens. Isso é resolvido pelas bobinas de deflexão vertical e horizontal. As bobinas de deflexão são também colocadas no "pescoço" do tubo, par a par, num arranjo como o observado nas Fig. 5 e 6, e elas são as responsáveis por desviar o feixe de elétrons por ação do campo magnético gerado pela bobina de deflexão vertical, horizontal ou por ambas.

\section{IV.5 Preparando o BDS e/m apparatus}

Para que o televisor possa ser utilizado nessa montagem, ele deve ser previamente preparado para tal ${ }^{9}$.

Como observamos anteriormente neste texto, a escolha por um televisor de 5 polegadas recai sobre o fato das tensões em seus circuitos serem muito mais baixas do que em qualquer outro televisor a partir de 10 polegadas. No entanto, algumas precauções de segurança devem ser tomadas ao manipular equipamentos eletrônicos. Se não se sentir seguro para realizar as operações aqui descritas solicite auxílio de uma pessoa habilitada na área de eletrônica ou mais experiente.

O primeiro passo é desconectar as bobinas de deflexão vertical e horizontal dos circuitos que as controlam. Com o televisor desligado e aberto, localize o arranjo de bobinas envolto ao "pescoço" do tubo e com um alicate, corte os quatro fios ligados a elas (Fig. 7). Depois, desconecte o soquete do tubo de raios catódicos, solte o parafuso que fixa a bobina no pescoço do tubo e a retire. Conecte novamente o soquete do tubo de raios catódicos.

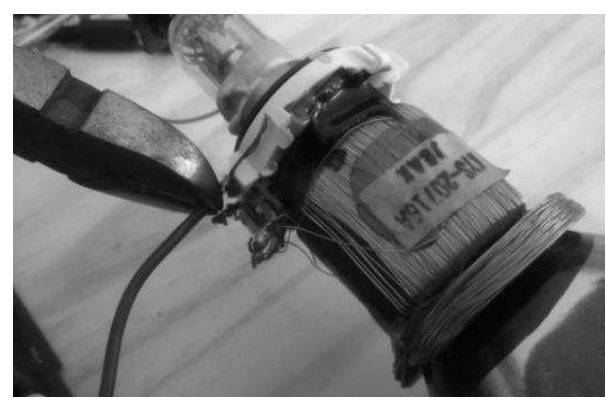

Fig. 7 - Preparação do BDS e/m apparatus: corte dos fios. Fonte: acervo dos autores.

ora paralelo, ora perpendicular, às linhas do campo magnético terrestre. Nessas duas situações o ponto de incidência inicial do elétron na tela irá modificar-se, para cima ou para baixo dependendo da orientação do tubo com relação ao campo magnético terrestre.

9 O aparelho de TV não necessita estar funcionando perfeitamente, basta que a tela esteja mostrando o brilho característico de uma TV ligada. Não é necessário que esteja sintonizando qualquer canal e até alguns defeitos são toleráveis, como os conhecidos horizontal ou vertical "queimados", caracterizados por uma faixa luminosa no centro da tela no sentido horizontal ou vertical, dependendo do defeito. 
Ao ligar novamente a TV, deve ser verificado em sua tela, apenas um ponto luminoso no centro. As bobinas deixaram de deflexionar o feixe de elétrons (Fig. 8). Perceba que o ponto no centro da tela do televisor não é tão pontual, o excesso de brilho causado pelo impacto dos elétrons contra a parede interna do tubo faz com que este ponto tenha um diâmetro aproximado de $2 \mathrm{~mm}$. Se a TV utilizada possuir controles de brilho, atue sobre este de forma a obter o ponto mais focado possível.

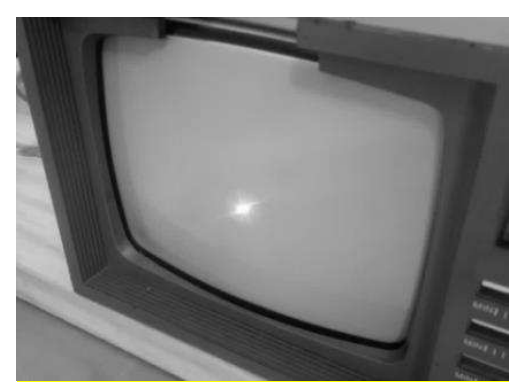

Fig. 8 - Preparação do BDS elm apparatus: um ponto luminoso. Fonte: acervo dos autores.

As bobinas presentes na TV são capazes de deflexionar o feixe de elétrons, contudo, seu formato irregular não permite que o campo magnético gerado seja uniforme, influenciando diretamente nos cálculos da relação $e / m$.

Uma das formas de se obter um campo magnético quase uniforme é por meio de um arranjo de bobinas conhecido como, bobina de Helmholtz (Fig. 9), idealizado por Hermann Ludwig Ferdinand von Helmholtz (1821-1894).

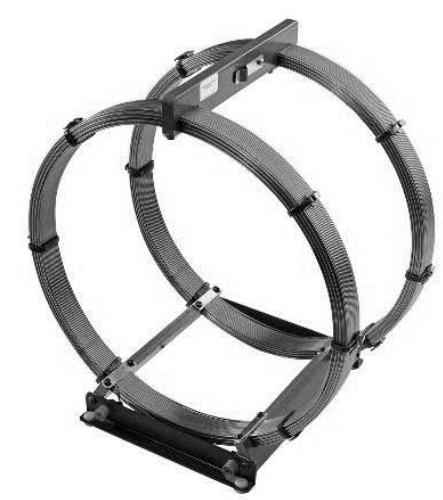

Fig. 9 - Bobina de Hemholtz. Fonte: <https:// www.3bscientific.com.br/bobinas-dehelmholtz-300-mm-1000906-u8481500-3b-scientific,p_880_2008.html>. 
O arranjo é formado por um par de bobinas circulares idênticas, coaxiais, ligadas em série ou em paralelo, de forma que, quando ligadas a uma fonte de tensão, uma mesma corrente elétrica percorra as bobinas em um mesmo sentido. De acordo com a teoria (TIPLER; MOSCA, 2009; SERWAY; JEWETT, 2012), ligar as bobinas em série exigirá que a fonte de alimentação forneça apenas metade da corrente elétrica que seria necessária em uma ligação em paralelo das bobinas, para um mesmo campo magnético gerado.

Os aspectos construtivos, as particularidades experimentais e a teoria relacionada ao funcionamento da bobina de Helmholtz são detalhadamente apresentados no trabalho de Robert (RENÊ, 2003). De forma resumida, o campo magnético no centro do espaço entre as bobinas será máximo e mais uniforme quando a distância de separação das bobinas for igual ao raio das bobinas (NETO, 2015; MARTINS, 1975).

Para nosso experimento, construímos a bobina de Helmholtz apresentadas na Fig. 10. As bobinas são construídas sobre uma base circular com diâmetro de $60 \mathrm{~mm}$ e são constituídas por 100 voltas de fio esmaltado de $0,36 \mathrm{~mm}$ (27 AWG), aproveitado da própria bobina de deflexão da TV. A estrutura sobre a qual a bobina foi enrolada é feita de material plástico, recortado de uma embalagem para produtos industrializados, com um comprimento adequado para formar um círculo de $60 \mathrm{~mm}$ de diâmetro (aproximadamente 188,50 mm mais $30 \mathrm{~mm}$ para fixação das pontas) e $20 \mathrm{~mm}$ de largura. Em nossa montagem cada uma das bobinas ficou com uma resistência aproximada de $6 \Omega$.

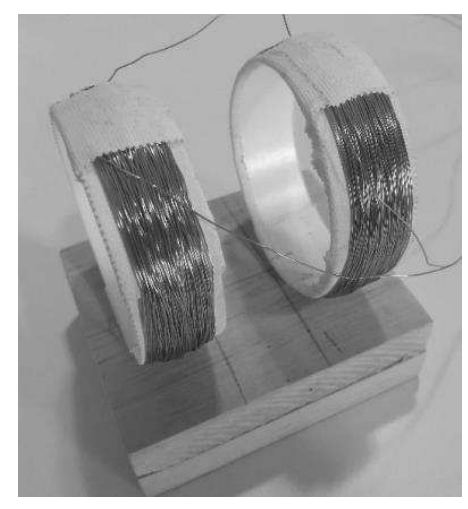

Fig. 10 - Bobina de Helmholtz construída para o experimento. Fonte: acervo dos autores.

Depois de finalizadas, as bobinas receberam algumas voltas de fita do tipo crepe (também pode-se utilizar fita do tipo isolante) para mantê-las na forma desejada e foram afixadas em uma base de madeira, separadas $30 \mathrm{~mm}$ uma da outra, utilizando-se cola quente. A base de madeira foi escolhida de forma que a altura do centro das bobinas correspondesse à altura do pescoço do tubo de raios catódicos (Fig. 11a). 


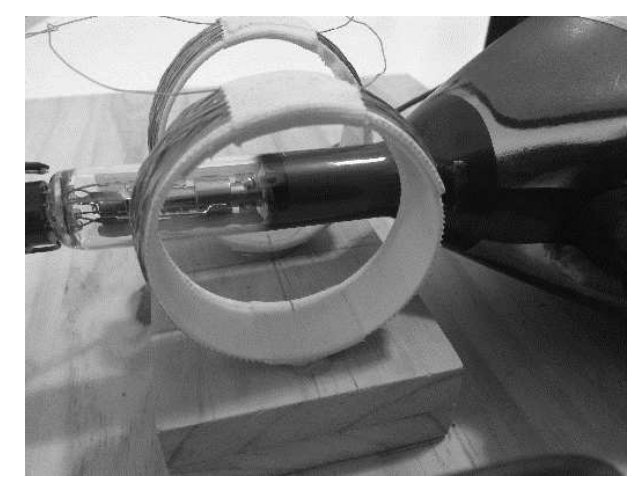

Fig. 11a-Montagem das bobinas no tubo de raios catódicos. Fonte: acervo dos autores.

O campo magnético gerado entre as bobinas de Helmholtz pode ser calculado pela fórmula,

$$
B=\frac{8 \mu_{0} N i}{5^{\frac{3}{2}} R}
$$

onde, $B$ é o campo magnético em tesla $(\mathrm{T}), \mu_{0}$ é a permeabilidade magnética do vácuo, $N$ é o número de espiras de cada bobina, $i$ é corrente circulante nas bobinas em amperes (A) e $R$ é o raio das bobinas (RENÊ, 2003).

Vamos agora testar se a bobina de Helmholtz pode realmente deflexionar o feixe de elétrons. O tubo de raios catódicos e as bobinas devem estar dispostos conforme a Fig. 11a.

Ajuste a fonte de tensão variável para zero volt, e a mantenha desligada. Conecte a fonte de tensão variável ao arranjo de bobinas conforme esquema da Fig. 11b (lembre-se que as bobinas devem estar ligadas uma a outra, de forma paralela ou em série), ligue a TV e a fonte.

\section{Fonte de tensão ajustável}

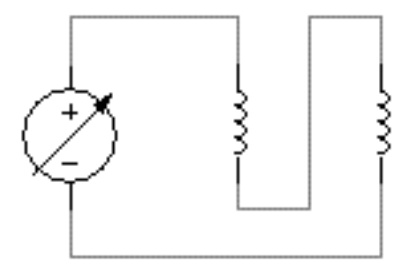

Bobina de Helmholtz

Fig. 11 -Esquema de ligação da fonte variável à bobina de Helmholtz. Fonte: autores.

Comece a variar lentamente a tensão da fonte e verifique se o ponto no centro da tela se desloca e em qual direção. Caso o ponto desapareça ao realizar algum destes testes, verifique com um multímetro se a tensão da fonte é realmente nula ao ajustá-la para zero volt. $\mathrm{O}$ ponto pode ter se deslocado tanto, em decorrência de uma possível tensão (e a correspondente corrente) "elevada", que saiu da área visível da tela. Inverta a polaridade da fonte, refaça os procedimentos indicados e verifique como o feixe de elétrons varia sua posição na tela. 
Nos kits comerciais e/m apparatus a alta tensão responsável pelo arrasto das partículas é fornecida por uma fonte de alta tensão de valor conhecido e o campo magnético gerado pelas bobinas pode ser calculado, uma vez que são conhecidos seus diâmetros, espaçamento e corrente elétrica circulante. $\mathrm{Na} \mathrm{TV}$, não conhecemos o valor exato da alta tensão oferecida pelo flyback e a bobina que construímos não é uma bobina perfeita de Helmholtz, de modo que precisamos encontrar soluções para medir estas duas grandezas.

Precisamos então, conhecer o valor da tensão $V$ de aceleração dos elétrons, que na TV é fornecida pelo flyback. Nesse modelo de TV, o valor médio da tensão de aceleração está em torno dos $5 \mathrm{kV}$. Mas, para medirmos com maior precisão esse valor, devemos utilizar uma ponta de prova de alta tensão e um multímetro ${ }^{10}$. Para a realização da leitura conectaremos a ponta de prova de alta tensão ao multímetro (Fig. 12).

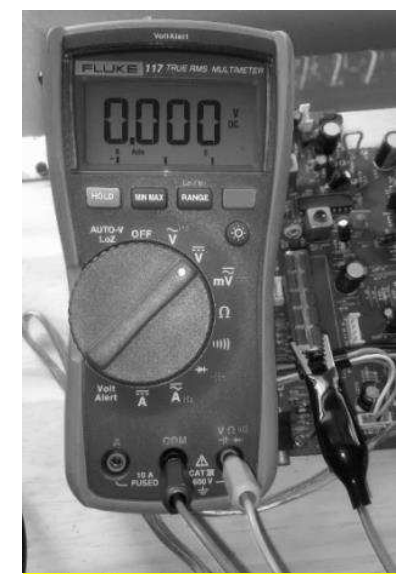

Fig. 12 - Conexão da ponta de prova ao multímetro e à um ponto negativo do chassi. Fonte: acervo dos autores.

O terminal ( - ) da ponta de prova de alta tensão deve ser ligado ao chassi (parte metálica) da TV e sua ponta (+) no local onde o fio que sai do flyback se conecta ao tubo de imagem (chupeta) (Fig. 13). O multímetro deve estar em uma escala de tensão com fundo de escala de $20 \mathrm{~V}$ e o valor da tensão medida deve ser multiplicado por 100 (se utilizada a versão de Tamiet (2015)).

Por tratar-se de medidas de alta tensão, novamente alertamos que os procedimentos aqui relatados oferecem risco ao operador do equipamento e devem ser realizados tomando todas as precauções de segurança necessárias, preferencialmente por pessoal capacitado, ou sob supervisão deste.

\footnotetext{
10 Nosso projeto prevê um custo reduzido do material utilizado, desse modo indicamos as propostas de Braga (2016) e Tamiet (2015) para a construção de pontas de prova de alta tensão com arranjos de resistores conhecidos como divisores de tensão. Ambas a um custo médio de 20 reais (valor estimado na cidade de São Paulo, em dezembro de 2018).
} 


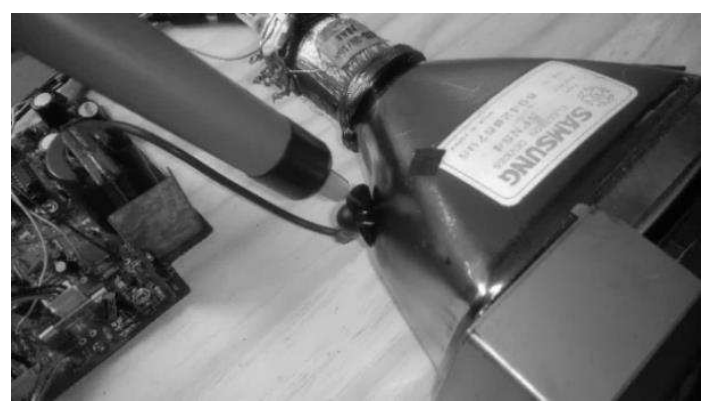

Fig. 13 - Medição da alta tensão. Fonte: acervo dos autores.

A última variável a que temos acesso e podemos medir é o campo magnético fornecido pelas bobinas para uma dada deflexão do feixe de raios catódicos.

Para se obter este dado, executaremos o seguinte procedimento:

- com a TV desligada ajustar a fonte de tensão variável para zero volt e ligá-la à bobina de Helmholtz de acordo com as Fig. 11b e 14;

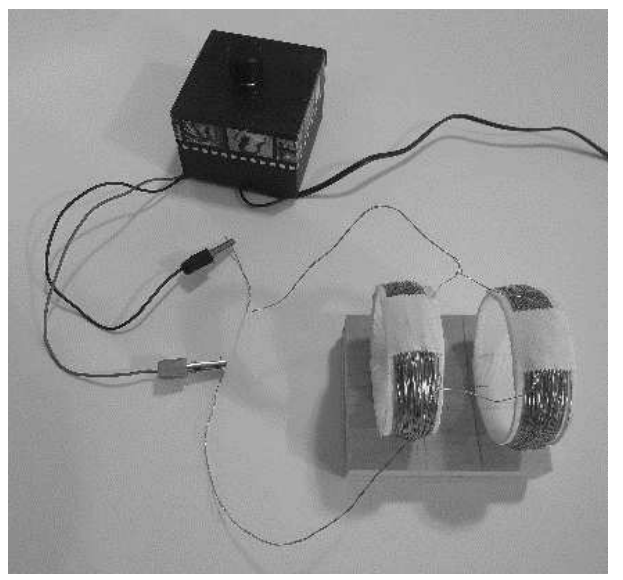

Fig. 14 - Ligação da fonte variável à bobina de Helmholtz. Fonte: acervo dos autores.

- ligar a TV e variar a tensão da fonte fazendo com que o ponto luminoso que estava no centro da tela se mova verticalmente. Medir e anotar a distância de deslocamento. Essa tarefa pode ser facilitada, preparando-se previamente uma escala de distâncias em um pedaço de papel, e fixando essa escala na tela da TV com uma fita tipo durex. Desligar a TV e a fonte variável sem desconectá-la da bobina e sem mexer no ajuste de tensão. Em nossos testes, a corrente elétrica nas bobinas alcançou valores médios de $600 \mathrm{~mA}$, um valor considerado alto para a bitola do fio utilizado na construção da bobina. Por esse motivo, evite manter a fonte de tensão ligada e conectada a bobina por períodos prolongados, pois o calor gerado pelo efeito Joule pode danificar o esmalte isolante do fio; 
- montar o circuito da Fig. 15a com o sensor de efeito hall, de forma que os fios que vão ligados aos terminais do sensor tenham um comprimento mínimo de $150 \mathrm{~mm}$. Apresentamos uma sugestão de montagem na Fig. 15b;

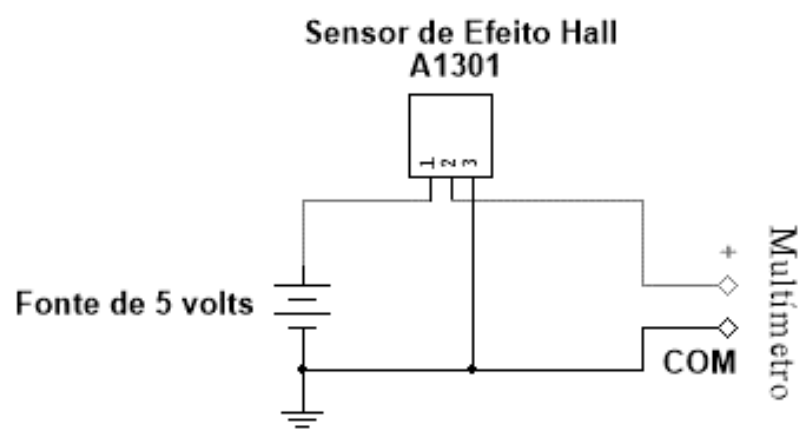

Fig. 15a-Circuito para medição do campo magnético. Fonte: autores.

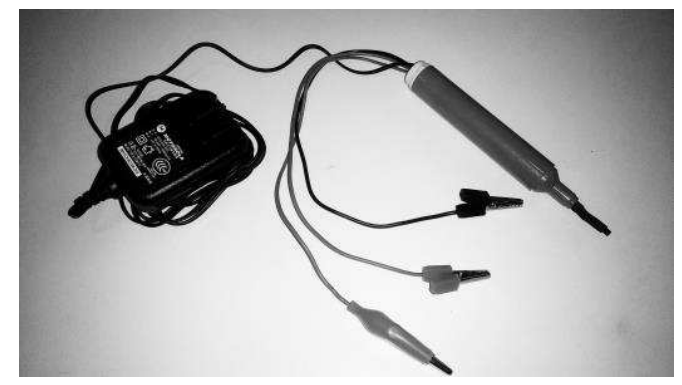

Fig. 15 - Sugestão de circuito para medição do campo magnético - Gaussímetro.

Fonte: acervo dos autores.

- retirar o conjunto de bobinas do "pescoço" do tubo de imagem;

- agora, com as bobinas fora do tubo de imagem, ligar novamente a fonte (a tensão na fonte deve ser a mesma de quando a deflexão do ponto foi medida) e colocar o sensor de efeito hall no centro da bobina, com sua face num ângulo de $90^{\circ}$ graus com a direção do campo magnético no interior da bobina ${ }^{11}$ (Fig. 16).

\footnotetext{
${ }^{11}$ A direção do campo magnético no interior da bobina pode ser determinada por meio da regra da mão direita se conhecermos as direções da deflexão (direção da força magnética) e da velocidade da partícula. Consulte como exemplo, Serway e Jewett, Jr. (2004, p. 820-825).
} 


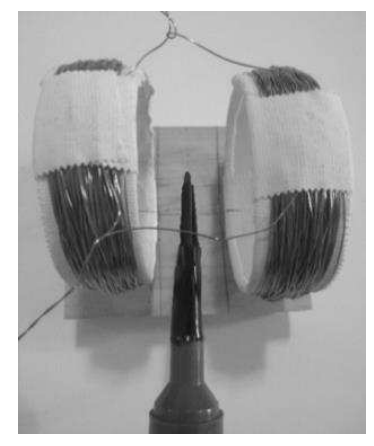

Fig. 16 - Medição do campo magnético no interior da bobina. Fonte: acervo dos autores.

Utilizando como referência as folhas de dados do componente (ELECTRONIC COMPONENTS DATASHEET SEARCH, 2016) e o artigo "make a magneto-meter" (MAKE A MAGNETOMETER, 2016) vamos a uma sucinta explicação do funcionamento do nosso Gaussímetro:

- o sensor de efeito hall A1308 ou outro equivalente, quando polarizado (ligado conforme a Fig. 15a) e não imerso em um campo magnético, fornece na saída Vout (pino 2 do componente) uma tensão correspondente à metade da tensão de entrada (no nosso caso, 2,5 V). Perceba que a qualidade da fonte de tensão influenciará diretamente no resultado final da medição, dê preferência a uma fonte que possa fornecer uma tensão estabilizada confiável de 5 V (carregadores de celulares são excelentes opções, mesmo os de modelos de celulares antigos);

- quando submetido a um campo magnético (perpendicular à face do componente), a tensão de saída sofre um incremento ou decremento de $2,5 \mathrm{mV} / \mathrm{G}$ (milivolt por gauss), ou seja, um incremento ou decremento de $50 \mathrm{mV}$ indica que o sensor está sendo atravessado por um campo magnético de $20 \mathrm{G}$;

- essas tensões devem ser medidas com uma escala de $20 \mathrm{~V}$ ou menos para que as pequenas variações nas tensões possam ser percebidas; e

- um detalhe a ser observado é que o sensor fornece de forma indireta uma leitura do campo magnético em G, no entanto, a equação que utilizaremos para o cálculo da relação carga/massa do elétron prevê que o campo magnético seja fornecido em $\mathrm{T}$, sendo necessário realizarmos a conversão de unidades: $1 \mathrm{G}=10^{-4} \mathrm{~T}$.

Agora estamos aptos a verificar a relação $e / m$ das partículas no interior do tubo de raios catódicos. Recorrendo às equações (15) e (18) ou à equação (19), podemos realizar os cálculos. Em qualquer caso, as variáveis necessárias são as descritas no Quadro 1.

Obviamente, um experimento com essas características, utilizando-se de soluções de custo reduzido para os equipamentos e instrumentos, não pode apresentar uma fidelidade comparável àquela oferecida, por exemplo, pelos kits já citados nesse artigo, no entanto, nas experiências realizadas com o BDS e/m apparatus foram encontrados erros da ordem de $25 \%$ em relação ao valor atualmente aceito para a relação carga/massa do elétron. 
Na Fig. 17 apresentamos nossa montagem final para o BDS e/m apparatus.

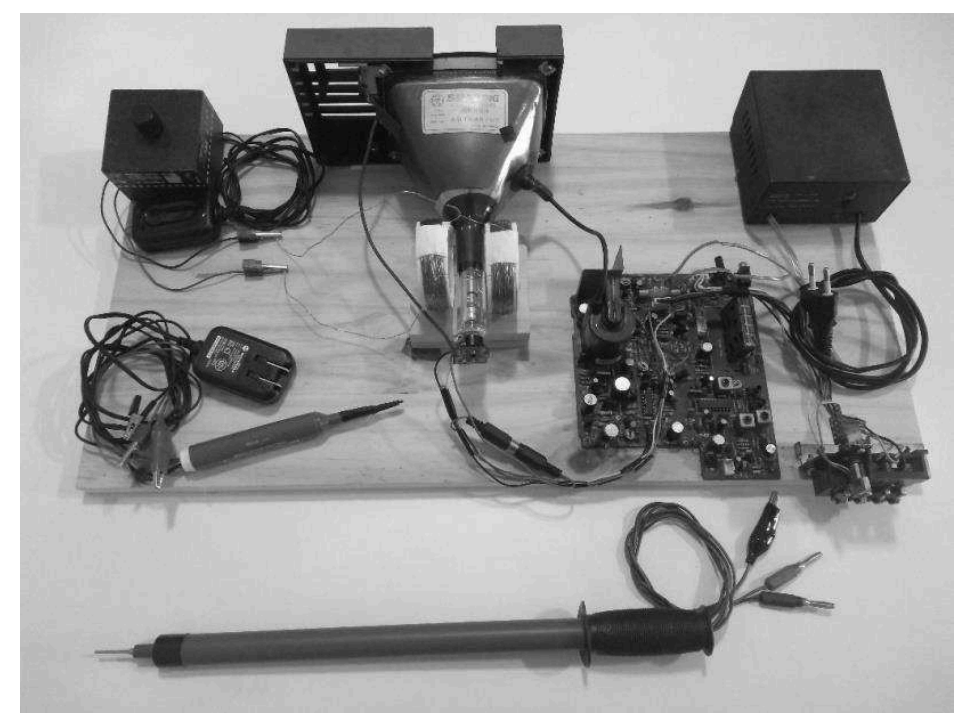

Fig. 17 - Versão final do DBS elm apparatus. Fonte: acervo dos autores.

\section{IV.6 Resultados experimentais}

Seguem abaixo alguns resultados experimentais obtidos com o BDS e/m apparatus.

Tabela 1 - Resultados experimentais obtidos com o BDS e/m apparatus. Feixe de elétrons paralelo as linhas do campo magnético da terra.

\begin{tabular}{|c|c|c|c|c|c|}
\hline $\begin{array}{l}\qquad d_{\operatorname{mag}} \\
\text { Deflexão do feixe na tela do tubo de } \\
\text { raios catódicos. (variável medida) }\end{array}$ & $0,035 \mathrm{~m}$ & $0,035 \mathrm{~m}$ & $0,035 \mathrm{~m}$ & $0,035 \mathrm{~m}$ & $0,035 \mathrm{~m}$ \\
\hline $\begin{array}{l}\text { Comprimento da região de influência } \\
\text { do campo magnético. (variável me- } \\
\text { dida) }\end{array}$ & $0,064 \mathrm{~m}$ & $0,064 \mathrm{~m}$ & $0,064 \mathrm{~m}$ & $0,064 \mathrm{~m}$ & $0,064 \mathrm{~m}$ \\
\hline $\begin{array}{l}\qquad L \\
\text { Comprimento da região de arrasto. } \\
\text { (variável medida) }\end{array}$ & $0,116 \mathrm{~m}$ & $0,116 \mathrm{~m}$ & $0,116 \mathrm{~m}$ & $0,116 \mathrm{~m}$ & $0,116 \mathrm{~m}$ \\
\hline $\begin{array}{l}\qquad V \\
\text { Tensão de aceleração dos elétrons. } \\
\text { (variável medida) }\end{array}$ & $5130 \mathrm{~V}$ & $5118 \mathrm{~V}$ & $5108 \mathrm{~V}$ & $5060 \mathrm{~V}$ & $5180 \mathrm{~V}$ \\
\hline \begin{tabular}{l}
\multicolumn{1}{c}{$B$} \\
Intensidade do campo magnético \\
responsável pela força de deflexão \\
do feixe de elétrons. (variável medi- \\
da indiretamente)
\end{tabular} & $0,00132 \mathrm{~T}$ & $0,00132 \mathrm{~T}$ & $0,00132 \mathrm{~T}$ & $0,00132 \mathrm{~T}$ & $0,00132 \mathrm{~T}$ \\
\hline $\begin{array}{l}v \\
\text { Velocidade de translação dos elé- } \\
\text { trons no interior do tubo de raios } \\
\text { catódicos. (variável calculada) }\end{array}$ & $\begin{array}{c}3,6644.10^{7} \\
\mathrm{~m} / \mathrm{s}\end{array}$ & $\begin{array}{l}3,6558.10^{7} \\
\mathrm{~m} / \mathrm{s}\end{array}$ & $\begin{array}{c}3,6487.10^{7} \\
\mathrm{~m} / \mathrm{s}\end{array}$ & $\begin{array}{l}3,6144.10^{7} \\
\mathrm{~m} / \mathrm{s}\end{array}$ & $\begin{array}{c}3,7001.10^{7} \\
\mathrm{~m} / \mathrm{s}\end{array}$ \\
\hline $\begin{array}{c}e / m \\
\text { Relação carga massa das partículas }\end{array}$ & $\begin{array}{c}1,30876.10^{11} \\
\mathrm{C} / \mathrm{Kg}\end{array}$ & $\begin{array}{l}1,3057.10^{11} \\
\mathrm{C} / \mathrm{Kg}\end{array}$ & $\begin{array}{c}1,3032.10^{11} \\
\mathrm{C} / \mathrm{Kg}\end{array}$ & $\begin{array}{l}1,2909.10^{11} \\
\mathrm{C} / \mathrm{Kg}\end{array}$ & $\begin{array}{c}1,3215.10^{11} \\
\mathrm{C} / \mathrm{Kg}\end{array}$ \\
\hline
\end{tabular}




\begin{tabular}{l|l|l|l|l|l}
\hline $\begin{array}{l}\text { constituintes dos raios catódicos. } \\
\text { (valor calculado) }\end{array}$ & & & & \\
\hline $\begin{array}{l}\text { Diferença em relação ao valor atu- } \\
\text { almente aceito como correto. Em } \\
\text { porcentagem. (valor calculado) }\end{array}$ & $25,60 \%$ & $25,77 \%$ & $25,92 \%$ & $26,61 \%$ & $24,87 \%$ \\
\hline
\end{tabular}

O valor médio encontrado para a relação $e / m$ foi de $1,3060.10^{11} \mathrm{C} / \mathrm{Kg}$ (coulomb por quilograma), correspondendo a uma discrepância média de 25,75 \% com relação ao valor atualmente aceito como correto, $1,7559.10^{11} \mathrm{C} / \mathrm{Kg}$.

Ao realizar o experimento com o tubo de raios catódicos, disposto de forma que o feixe de elétrons ficasse perpendicular às linhas do campo magnético terrestre (portanto, sofrendo a influência máxima desse campo, segundo a equação da força de Lorentz), a discrepância média entre os valores encontrados e aquele aceito como correto foi de aproximadamente $30 \%$. Esse dado sugere que o campo magnético terrestre influência a trajetória do feixe de elétrons, mesmo sob as condições encontradas no interior do tubo (alta tensão de aceleração gerada pelo flyback e campo magnético gerado pelas bobinas de deflexão).

Sugerimos que durante o levantamento de dados, também seja medida a corrente elétrica na bobina de Helmholtz, e com o auxílio da equação (20), seja comparado o valor do campo magnético medido com o sensor de efeito Hall com o calculado. Em nossa montagem a diferença foi da ordem de $28 \%$.

Optamos por não realizar um tratamento estatístico mais denso dos valores obtidos experimentalmente, por compreendermos não ser esse o principal objetivo do trabalho. Contudo, podemos indicar que algumas das incertezas de nossas medidas estão diretamente relacionadas à resolução e à precisão dos nossos instrumentos de medida

- régua: resolução de $1 \mathrm{~mm}$; e

- multímetro: resolução de $1 \mathrm{mV}$ e $10 \mathrm{~mA}$, e precisão de $\pm 0,5 \%$ na escala de tensão e $\pm 2 \%$ na escala de corrente.

Não tivemos condições de identificar a precisão da régua utilizada nas medições.

\section{Considerações finais}

A realização desse experimento mobiliza diferentes conceitos, teorias e procedimentos experimentais que são relevantes para o Ensino de Física, principalmente, porque o estudante vivencia uma prática que confere significado às abordagens teóricas acerca de tais conceitos. 
A despeito da margem de erro obtida em relação ao valor para a relação carga/massa do elétron, todas as etapas do procedimento experimental mobilizam requisitos formativos aos estudantes. A variação do erro está intimamente ligada à qualidade dos equipamentos e à presteza das medições, podendo ser minimizado. Fontes estabilizadas e reguladas de melhor qualidade oferecerão resultados mais próximos aos da literatura. Assim como, um posicionamento incorreto do sensor de efeito Hall ou uma imprecisão da medição da deflexão do feixe de elétrons (deslocamento do ponto na tela) tendem a acrescer algum erro ao resultado final. No entanto, todos esses desvios são ótimos exemplos para que os professores explicitem e discutam aspectos da natureza das Ciências, tal como, o papel do erro na experimentação científica, relembrando inclusive que Thomson e seus contemporâneos, enfrentaram problemas semelhantes durante a realização de seus experimentos ao final do século XIX. Uma outra opção, seria explorar junto com os alunos quais as influências das "deficiências" ou limitações do equipamento (Gaussímetro, fonte variável, bobinas de deflexão, ponta de prova de alta tensão e tubo de raios catódicos) frente aos erros encontrados, utilizando a anomalia resultante como uma nova perspectiva ou possibilidade de explicação para os fenômenos, conforme Kuhn (2013) observa.

Para exemplificar os limites de uma determinada solução científica, o professor pode sugerir que seus alunos utilizem as duas equações apresentadas para a deflexão magnética dos raios catódicos (equações 1 e 11), inserindo seus dados de medição e verificando qual solução apresenta um resultado para a relação carga/massa do elétron mais próxima à da literatura.

A fundamentação teórica referente aos conceitos e fenômenos físicos presentes no experimento requer um estudo sobre cargas elétricas, campo elétrico, campo magnético, campo magnético criado por uma bobina, bobina de Helmholtz, força elétrica, força magnética, força de Lorentz, potencial elétrico, energia cinética, trabalho, conservação da energia, segunda lei de Newton, corrente elétrica, diferença de potencial elétrico, resistores, lei de ohm, divisor de tensão resistivo, transformadores, energia interna, emissão termiônica, função de extração, fluorescência, fosforescência, entre outros, todos assuntos presentes no currículo da Física do Ensino Médio e amplamente explorados em livros didáticos. Muitos desses assuntos provavelmente já devem ter sido introduzidos no curso em que se utilizaria o experimento em questão. O professor pode solicitar que os alunos expliquem conceitualmente e com base na teoria previamente estudada, o que acontece em cada situação observada no experimento, indo ao encontro da defesa de Bachelard ([1938] 1996) de que o aluno ou aprendiz deve saber extrair do concreto, o abstrato. 
Essa proposta pode ainda oferecer soluções para outros problemas apontados por professores ou pesquisadores da área. Por exemplo, o alto custo dos equipamentos e a falta de tempo para realização de experimentos. Como apontado por Ramos (2016), uma solução experimental que substitua equipamentos com custo relativamente alto, por algo em torno da metade do seu valor, já pode ser considerado como de custo reduzido. Nessa proposta, estamos substituindo um kit com custo aproximado de 2500 dólares ${ }^{12}$, por algo em torno de 80 dólares. Sendo que todo o material pode ser encontrado no mercado nacional. Cabe considerar que os materiais utilizados nesse experimento podem ser aproveitados em inúmeros outros experimentos no Ensino de Ciências.

Ainda que o BDS e/m apparatus não ofereça a mesma exatidão dos kits comerciais, a margem de erro média é de $25 \%$, ele permite que o estudante manipule e visualize todo o processo para a obtenção da relação carga/massa do elétron. Isso contribui para a organização e a correlação de informações necessárias à elaboração dos conceitos fundamentais desejados para o aprendizado desse tópico da Física. Esse experimento é uma oportunidade de integrar a teoria à prática e tornar sólida a aprendizagem do experimento de Thomson, exaustivamente apresentado em manuais de Física e Química do Ensino Básico brasileiro.

Para lidar com a falta de tempo para desenvolver experimentos (MARCONDES, 2007), propomos como alternativas, que experimentos desse tipo, uma vez montados, sejam utilizados ao longo do ano, ou de um semestre, para observar e medir outras grandezas físicas, fazendo com que os estudantes avancem e resolvam cada problema ou dificuldade encontrada, conforme vão progredindo nos assuntos na sala de aula, tanto com a intervenção e mediação do professor, quanto de forma autônoma com um maior grau de liberdade (CARVALHO, 2010; HEERING, 2014).

Ainda, acreditamos ser este um excelente exemplo para ilustrar como um experimento não serve apenas para comprovar uma teoria, mas também para apresentar uma aplicação desta (KUHN, 2013). Nesse caso, uma aplicação tecnológica, o que em algum sentido pode tornar a aprendizagem significativa para os alunos.

Ademais, pode ser utilizada para discutir a matematização e concepção teórica prévia implícita na montagem experimental. Nos cursos de Licenciatura, por exemplo, os formadores de professores podem destacar o fato de que nenhuma experimentação é neutra ou independente de um prévio conhecimento de algum dos fenômenos possivelmente observados, como bem elucidou Gil-Pérez et al. (2001). O conhecimento de conceitos atuais e as concepções sobre a natureza da matéria guia a interpretação dos fenômenos que se observa.

\footnotetext{
12 Consideramos o valor em dólares, utilizando a taxa de câmbio do dia 10/02/2019, visando que quando o artigo for lido futuramente, os valores possam ser, possivelmente, melhor dimensionados.
} 
Quando essa proposta experimental é aliada a uma abordagem histórica, exemplificase mais aspectos da natureza das ciências, como, por exemplo, as dificuldades práticas que surgem ao se tentar desenvolver uma solução experimental, situação que enfrentarão muitos daqueles que se propuserem a implementar esta adaptação. Ou ainda, as inúmeras contribuições de diferentes cientistas, algumas, inclusive, contestadas por grupos de opiniões opostas, até que se alcançasse um razoável consenso sobre a natureza dos raios catódicos. Além de tudo, o estudo de episódios históricos, como o dos experimentos sobre raios catódicos, é um poderoso instrumento para promover a compreensão de conceitos e fenômenos físicos relacionados ao tema, com exemplo, Cathode Rays (THOMSON, [1897] 1958) configura-se um excelente exemplo dos potenciais usos das Histórias das Ciências no ensino.

\section{Referências}

ARAÚJO, M. S. T.; ABIB, M. L. V. S. Atividades experimentais no ensino de Física: diferentes enfoques, diferentes finalidades. Revista Brasileira de Ensino de Física, v. 25, n. $2,2003$.

BACHELARD, G. A formação do espírito científico: contribuição para uma psicanálise do conhecimento. Rio de Janeiro: Contraponto, [1938] 1996.

BRAGA, N. C. Fontes de alimentação. São Paulo: Saber, 2005.

. Construa uma ponta de alta tensão para o multímetro. Disponível em: $<$ http://www.newtoncbraga.com.br/index.php/eletronica/57-artigos-e-projetos/8530-construauma-ponta-de-alta-tensao-para-o-multimetro-art1467>. Acesso em: 30 abr. 2018.

CARLIN, N. et al. Estudo experimental do movimento de partículas carregadas em campos elétricos e magnéticos: seletor de velocidades. Revista Brasileira de Ensino de Física, v. 32, n. 2, 2009.

CARvalHo, A. M. P. Ensino de Ciências: unindo a pesquisa e a prática. São Paulo: Cengage Learning, 2004.

As práticas experimentais no Ensino de Física. In: A.M.P. Carvalho (Org.).

Ensino de física. São Paulo: Cengage Learning, 2010.

CARVAlHO, A. M. P.; GIL-PÉREZ, D. Formação de professores de Ciências Tendências e inovações. São Paulo: Cortez, 2011. v. 28.

DELIZOICOV, D.; ANGOTTI, J.A. Metodologia do Ensino de Ciências. São Paulo: Cortez, 2000.

Delizoicov, D.; AngotTi, J. A.; PernanbuCO, M. M., Ensino de Ciências Fundamentos e Métodos. São Paulo: Cortez, 2011. 
ELECTRONIC COMPONENTS DATASHEET SEARCH. Disponível em: $<$ http://www.alldatasheet.com/>. Acesso em: 30 abr. 2018.

GASPAR, A. Atividades experimentais no ensino de Física - Uma visão baseada na teoria de Vigotski. São Paulo: Livraria da Física, 2014.

GIL-PÉREZ, D. et al. Para uma imagem não deformada do trabalho científico, Ciência \& Educação, v. 7, n. 2, 2001.

HEERING, P. The stabilization of experimental procedures: historical and educational aspects. Revista Brasileira de História da Ciência, v. 7, n. 2, 2014.

KRAFTMAKHER, Y. Experiments and demonstrations in Physics. Singapura: Bar-Ilan Physics Laboratory, 2015.

KUHN, T. A estrutura das revoluções científicas. São Paulo: Perspectiva, 2013.

MAKE A MAGNETOMETER. Disponível em: <https://www.kjmagnetics.com/blog.asp?p =gaussmeter>. Acesso em: 30 abr. 2018.

MARCONDES, M. Oficinas Temáticas no Ensino Público. São Paulo: Imprensa Oficial do Estado de São Paulo, 2007.

MARTINS, N. Introdução à teoria da eletricidade e do magnetismo. São Paulo: Edgard Blücher, 1975.

MARTINS, R. A. Introdução: A História das Ciências e seus usos na educação. In: SILVA, C. C. (Org.). Estudos de história e filosofia das ciências: subsídios para aplicação no ensino. São Paulo: Livraria da Física, 2006.

MEDEIROS, A.; MONTEIRO Jr, F. N. Algumas tendências na utilização de reconstruções experimentais históricas no ensino de física. In: SEMINÁRIO DE HISTÓRIA DA CIÊNCIA, VIII, 2011, Rio de Janeiro. Disponível em: <http://alexandremedeirosfisicaastronomia. blogspot.com/2011/11/algumas-tendencias-na-utilizacao-de.html>. Acesso em: 30 abr. 2018.

MOREIRA, M. A. Enseñanza de la física: aprendizaje significativo, aprendizaje mecánico y criticidad. Revista de Enseñanza de la Física, In: XI CONFERENCIA INTERAMERICANA SOBRE ENSEÑANZA DE LA FÍSICA, 26, 1, 2013, Porto Alegre, v. 26, n. 1, 2014. Disponível em:<https://revistas.unc.edu.ar/index.php/revistaEF/article/view File/9515/10290>. Acesso em: 30 abr. 2018.

NETO, J. B. Teoria eletromagnética: parte clássica. São Paulo: Livraria da Física, 2015.

POZO, J.; CRESPO, M. A aprendizagem e o ensino de ciências: do conhecimento cotidiano ao conhecimento científico Porto Alegre: Artimed, 2009. 
RAMOS, E. O uso de materiais didáticos no ensino de Física. In: CONGRESSO DE PESQUISA DO ENSINO FÍSICA E QUÍMICA NA ESCOLA E NO MUNDO ACADÊMICO - O DESAFIO INTERDISCIPLINAR, 5, 2016, São Paulo.

RENÊ, R. Bobina de Helmholtz. Revista Brasileira de Ensino de Física, v. 25, n. 1, 2003.

SERWAY, R.; JEWETT Jr, J. Princípios de Física. São Paulo: Cengage Learning, 2004.

SILVA, L.; SANTOS, W.; DIAS, P. A carga específica do elétron - Um enfoque histórico experimental. Revista Brasileira de Ensino de Física, v. 33, n. 1, 2011.

SMITH, G. E. J.J. Thomson and the electron, 1897-1899. In: BUCHWALD, J. Z.; WARWICK, A. (Org.). Histories of the electron: the birth of microphysics 2. London: MIT Press, 2001.

TAMIET, L. Para medición de alto voltaje. Disponível em: <https://www. comunidadelectronicos.com/proyectos/sonda-AV.htm>. Acesso em: 30 abr. 2018.

THOMSON, J. J. Conduction of electricity through gases. Cambridge: Cambridge University Press, 1903. [Forgotten Books: Classic reprint series, 2012].

. Cathode rays. Philosophical Magazine, 44, p. 293-316, 1897. Republicado em SCHWARTZ, G. \& BISHOP, P. W. Moments of Discovery - Volume Two (The development of modern Science). New York: Basic Books, Inc, 1958.

THOMSON, J.; CALLICK, E. B. Electron physics and technology. London: The English Universities Press Ltd, 1959.

TIPLER, P.; MOSCA, G. Física para cientistas e engenheiros. Rio de Janeiro: Livros Técnicos e Científicos Editora, 2009.

TOWNSEND, J. S. E. Electricity in gases. Oxford: Clarendon Press, 1915.

TRIVELATO, S. F. SILVA, R. L. Ensino de Ciências. São Paulo: Cengage Learning, 2011.

WEINBERG, S. The discovery of subatomic particles. Cambridge: Cambridge University Press, 2003.

WHER, M. R.; RICHARD-Jr, J. Física do átomo. Rio de Janeiro: Ao Livro Técnico, 1965.

WHITTAKER, E. T. Theories of aether and electricity. Dublin: Longmans, Green, and Co., 1910.

ZANETIC, J.; MENEZES, L. C.; HOSOUME, Y. Grupo de reelaboração do ensino de física (GREF), Física 3 - Eletromagnetismo. São Paulo: EDUSP, 2000. 